\title{
Critical Frameworks for Graphic Design: Graphic Design and Visual Culture
}

This paper is about an ongoing yet urgent interest which is: how best to account for graphic design? It will examine the potential of Visual Culture as an approach and demonstrate what it has to offer. ${ }^{1}$ Awareness of both the limitations of particular disciplines, and, the rewards of interdisciplinarity inform the position taken. As will be shown, despite a history of interventions and debates, from both within and without the subject of graphic design there has been a lack of attention to Visual Culture and its relevance.

Graphic design remains underdeveloped as a discipline; in comparison to its design neighbours (architecture, industrial design), its fine art neighbours, and its theory neighbours (cultural studies, media studies, visual culture) - it is barely recognised. This is not to under value new work and scholarship which appears ${ }^{2}$ but to recognise the need for rethinking and re-positioning the subject. Perhaps part of the problem is its location at the intersection of design, media and culture so that none of the disciplines truly welcomes its inclusion. An interdisciplinary approach would seem to offer benefits but has been elusive. This paper argues that an approach based on Visual Culture would be highly relevant and productive, and culminates in considering what questions such an approach would bring to a classic example of graphic design history. The paper starts by exploring in some depth the relationship between Visual Culture and graphic design by considering the emergence of Visual Culture as a discipline, and the reaction from relevant design communities : design history, graphic design history and graphic design criticism.

\section{Visual Culture}

So what is meant by the term Visual Culture and what is its provenance? Visual Culture has emerged relatively recently to find academic recognition. Visual Culture now appears in book, journal and course titles, professorships, and conferences. It is endorsed yet strangely amorphous. Books such as those by Jenks (1995), Walker and Chaplin, (1997) Evans and Hall (1999) and Mirzoeff (1999) all appeared in the late 1990's, which was a key moment in considering the historiography of Visual Culture. In terms of its origins there is no agreed definition or accepted view of its first use, indeed it remains hotly contested. Its genealogy is recounted in a number of sources 
(see Morra \& Smith 2006 for a comprehensive collection) and though there is always an argument to say that earlier precedents exist - most authors agree that the publication in 1996 of the responses to a questionnaire about Visual Culture from a range of leading academics in the journal October was pivotal ("Questionnaire,"1996, pp 25-70). The majority of the respondents were American art historians but the range included the fields of film, architecture and literature. That issue of October marked a moment, a reaction. The response by Svetlana Alpers, which acknowledges her use of the term "visual culture" in her work on Dutch painting published in the 1980's, carefully defines her use of it in a specific context, as if to disassociate it from the controversy (1996,p.26). The debate in October included some strong views on what was perceived as a threat to art history and a challenge to art historians, many of whom were highly critical of Visual Culture. In addition, in selecting key moments in this emergence of Visual Culture, the interest in "visuality," that is to say the culturally and historically specific modes of attention and viewing of the visual, is central. This is most notably evidenced by the symposium in 1988 and the related book "Vision and Visuality" edited by Hal Foster.

These are but selected highlights from a complex history which some might argue has many antecedents. It is entirely reasonable to consider for example the work of scholars such as Baxandall (cited by Alpers) as an important contributor to Visual Culture. In Painting and Experience in Fifteenth Century Italy (1974) Baxandall offered an alternative understanding and insight into Renaissance painting. He explored materiality, and indeed visuality, although he did not use that term, in a way which was entirely consistent with today's understanding of Visual Culture. John Berger publishing in the 1970's is also hugely formative for the development of Visual Culture. The controversial Ways of Seeing (1972) is from today's standpoint, a primer in Visual Culture. Can it be true that Berger dared to put a classical painting of a nude next to a soft porn image and ask us, the viewers, to see the connections? There are no doubt many opinions on where the origins of Visual Culture lie, however all the above have something in common. It is clear that that the origins lie in art history, and more specifically the scholarship of painting. Whether it is attributed to the 1970's, 1980's or indeed the 1990's, as part of the "new art history" which challenged the canon and traditional approaches to art history, is debateable.

By the late 1990 's, the potential of Visual Culture was taken up with enthusiasm by academics from a cultural studies background, and it moved from its art history roots, at least in the UK, into the territory of 
media and cultural studies. This is evidenced through publications such as Walker and Chaplin's Visual Culture: an introduction (1997) and Evans and Hall Visual Culture: The Reader (1999). The former has chapters on: institutions, the gaze, pleasure, and new technology. For anyone familiar with the theoretical discourse of cultural studies and media studies this is familiar territory- but thought through specifically in relation to the visual. The Evans and Hall reader, now a classic, contains a rich array of authors from the canonical Barthes, Benjamin and Foucault, to the influential work of Tagg, Silverman, and Dyer (Evans \& Hall, 1999). Visual Culture is no longer "art history with a difference" in these texts the tools of Cultural and Media Studies, concepts which have been carefully honed and argued through since the 1960's, are now being considered and developed in a new way; some might argue from a wholly different premise. The range of visual phenomena analysed was broad. In striking positions and defending new approaches for what was to be termed Visual Culture : film, television, photography, and advertising_were all part of its purview.

Whether in the context of art history or the context of cultural and media studies, what is so striking in all these debates which attempt to mark the territory in the mid to late 1990's, is the complete omission of the word "design" or of "design history". Nowhere in this complex moment with all the various accounts does design make itself heard as part of Visual Culture. Given that many British academics working in this field of Visual Culture would have been connected to what was a large network of art and design (history) departments, this is curious. More surprising perhaps is that graphic design which is specifically visual, and as Poynor has recently argued has a "central role " as a "shaper of the visual environment," (Poynor, 2011,para.21) is entirely absent from the debates and published works. Graphic Design should be a dream topic for analysis - with its messages, its target audiences, and its role in commodity culture. It is indeed as Poynor says, "unaccountable" that it has been ignored(Poynor,2011,para.21)

The further development of Visual Culture from the late 1990's can be seen in the fields of new media and photography. Here one can find analysis where longer histories in which to locate media forms beyond the discipline boundaries are suggested, and where viewing regimes are acknowledged in order to develop a richer understanding. For example Manovich in characterising the computer screen in "Language of New Media," locates this as part of a history and genealogy of screens, and by association, vision - citing Renaissance painting as a example of his first category of a" classical screen"(Manovich, 2001, p.95). Darley, in analysing computer games culture, goes beyond 
computing history, and frames gaming by looking back to pre-cinema and the nineteenth century preoccupation and familiarity with spectacle and illusion (Darley, 2000). Many other examples exist where authors were stepping outside of specific subject histories and making connections across the visual.

Also over time the recognition that Visual Culture has a relationship to Material Culture emerged. For example in the area of photography which was largely interrogated as image, some argued that photographs are also objects, artefacts that are collected and displayed and not exclusively visual (see Edwards, 2001). But this anthropological or "ethnographic turn " as it was coined in the 1990's (see Batchen, 2008) was not welcomed by many historians of art and culture. The photographic historian Batchen, in reviewing this debate and writing about Visual Culture and snapshot photography in 2008, defends the anthropological turn:

" Anthropology has traditionally looked at such [cultural] activity as something that has utilitarian value. Images are created for some purpose. Images do things. They are social objects, not simply aesthetic ones. They are meaningful only when seen in relationship to a wider social network of beliefs and practices, economies and exchanges."_(Batchen, 2008,p128)

How easily graphic design could be substituted for the word "images" here! So Visual Culture and its ethnographic turn would take as implicit that in attending to the practices and experience of looking, this would have to include everyday forms. So much graphic design would fall into this category of the everyday, and what is often referred to as the vernacular._Visual Culture embraced the ethnographic turn and was proudly interdisciplinary. As Martin Jay wrote in 2005, also reflecting back on key debates:

"Located somewhere at the crossroads of traditional art history, cinema, photography and new media studies, the philosophy of perception, the anthropology of the senses, and the burgeoning field of cultural studies it defied easy categorization." (Jay, 2005, p139)

\section{Design History}

Given this take up of Visual Culture within a number of critical fields and the considerable debate which occurred one might reasonably ask: what was the reaction and take up in the world of design? Since design is both visual and cultural there would be much to discuss and 
contribute; not least of which would have been to challenge the silence from visual cultural theorists to date on the inclusion of design. However a search based on two key journals Design issues (US) and Journal of Design History (UK) which would have been the most likely forums in this crucial period, suggest there was in fact no debate at all related to Visual Culture from the design academy. No doubt there are complex reasons for this, and for the paths which were taken. Perhaps if the journal Block had not ceased publication in the late 1980's it would have offered a platform for such a discourse to develop. It is fair to say that design history at this time was embracing material culture but not Visual Culture. This goes back to the central problem for graphic design - design history and criticism has traditionally been and continues to be largely focused on three-dimensional design, especially industrial design. One wonders if graphic design has been served well by its location within design history? Always the poor relation, graphic design is often the token paper or "special edition" of a journal. A survey of the last decade of the Journal of Design History shows how important consumption studies and material culture have become to design history. There were also major debates in Design Issues questioning methodologies and scope of study, for example in 1995 a whole edition is dedicated to debating Design History_and the idea of Design Studies. However they were not acknowledging the relevance of debates in Visual Culture. ${ }^{3}$ The only paper to actually address Visual Culture in relation to design is written as late as 2006 (Julier) and is written from a negative perspective which deliberately presents Visual Culture in a poor, reductionist light. Instead the author proposes a superior alternative (named Design Culture), which ironically Julier claims as more appropriate, by re-directing it towards three dimensional design rather than the visual.

\section{Graphic Design History and Criticism}

Perhaps then the place to look is the discourse of graphic design and the debates in the graphic design community in the 1990's. Surely here we will find attention to Visual Culture? It was a formative time for graphic design history, theory and criticism. It was dominated by an attempt to construct a critical discourse for graphic design which traversed practice and the academy, led by figures such as Rick Poynor in the UK and Ellen Lupton, Jessica Helfand, Andrew Blauvelt, Steven Heller, and Michael Rock from the US. Design journalism was key. New platforms such as EYE (UK) and Émigré (US) pioneered a new form of design criticism which encouraged debate and critique of both contemporary and historical graphic design. They went beyond the trade press formula, and helped to establish graphic design as worthy of study. New contributions to thinking about the history of 
graphic design, such as the small but highly regarded publication by Richard Hollis (1994)) were published, and graphic design educators, especially US based figures of McCoy, Wild and Burdick were highly influential. But, the concerns, at least the intellectual ones, were with a specific kind of theory: post-structuralist critical theory and especially Derrida's concept of "deconstruction". In a very real sense this came to stand for 'theory' for graphic design. From a UK perspective it received its biggest promotion from Cranbrook (Cranbrook Academy of Art) under Katherine McCoy: the American academics really developed and defended its relevance. ${ }^{4}$ Theory, in this case post-structuralist, was not always welcome, or indeed useful! Any theory will always have its supporters and detractors. But there are many kinds of theory and, looking back although it was an important time, it was dominated by certain obsessions. Since then research and understanding in graphic design has developed through graphic design criticism and graphic design history publications; but, the wider contextualisation through Visual Culture and its theoretical concerns remains largely absent, and has never been the subject of debate until recently (Poynor, 2011). Given its pivotal position between media and design this is a lost opportunity for the subject and its scholarship.

\section{Visual Culture and Graphic Design}

The case for Visual Culture is strong for a number of reasons: graphic design is surprisingly complex and Visual Culture is an approach which can accommodate these complexities and serve the subject well. Graphic design plays a key part in the visual environment (i.e. what Visual Culture is referencing); it relies on cultural understanding and de-coding, audiences and viewing conditions ( what visuality and the ethnographic turn seek to address). Contemporary graphic design crosses media of print and screen - all of which Visual Culture can handle as an inclusive interdisciplinary approach. Also is it not the case that graphic designers draw on their visual culture when designing? It seems so obvious in that light to develop frameworks which analyse these visual cultural contexts to better understand the work. In short, it suits the subject of graphic design. In addition graphic design has been the poor relation in design history and remains underdeveloped. Graphic design history, more specifically, despite its achievements and champions (Heller 2011) is limited in its approach. This is inevitable as it seeks defensively to establish a territory, a subject, which has been hard won. But graphic design history has remained confined to comparing graphic design with graphic design as the basis for telling us what we need to know. This is not to undervalue the important work achieved but to question whether the insights could be more 
profound. In a sense heroes of graphic design history such as Toulouse-Lautrec for poster design or modernist designers such as Moholy-Nagy or El Lissitzky, were practitioners of Visual Culture creating artefacts which crossed boundaries of art, design and media. We have chosen to create boundaries and divide off the work for analysis, but does this make sense? For the subject to grow the approach needs to be more interdisciplinary thereby genuinely accounting for the complex cultural role and agency of graphic design in our visual experience of the world. Also we need to engage a wider academic community beyond design history and graphic design to further develop the subject and scholarship. This latter point was made recently by Poynor (2011) and is yet another important aspect to the development of appropriate critical frameworks.

What then would approaching graphic design from a visual cultural perspective mean? There is no monolithic theory that simply needs to be "applied" but there is a set of concerns. Visual Culture pays attention to historical conventions in visual communication so in discussing graphic language we might refer to dominant traditions which relate to painting, or the impact of photography, rather than purely graphic design precedents. Technologies of vision and media are a significant aspect of Visual Culture - not only in terms of production and materiality but also in terms of visuality. In addition ways of looking and their power relations, contexts for engaging and consuming images are all relevant. Vision is understood to be active:

"The capacity to see is educated and disciplined, habituated and interested, and primed to be alert or dormant in one way or another; ways that are specific to culture and history."(Lister et al, 2009 p.101)

Thus one aspect of the analysis of graphic design would be to better understand, through research, the cultural eye of the audience of that time which in turn relates to the cultural eye of the designer.

The analysis of an iconic example from Graphic Design History will serve to think through these ideas: the poster for the Moulin Rouge "La Goulue" by Toulouse-Lautrec dated 1891. (See figure below). The poster promotes a relatively new cabaret venue in Paris, the Moulin Rouge in Montmartre, by showcasing two of its well known dancers, Louise Weber (aka La Goulue ) and Jacques Renaudin (aka Valentin le Désossé) in front of an audience. 


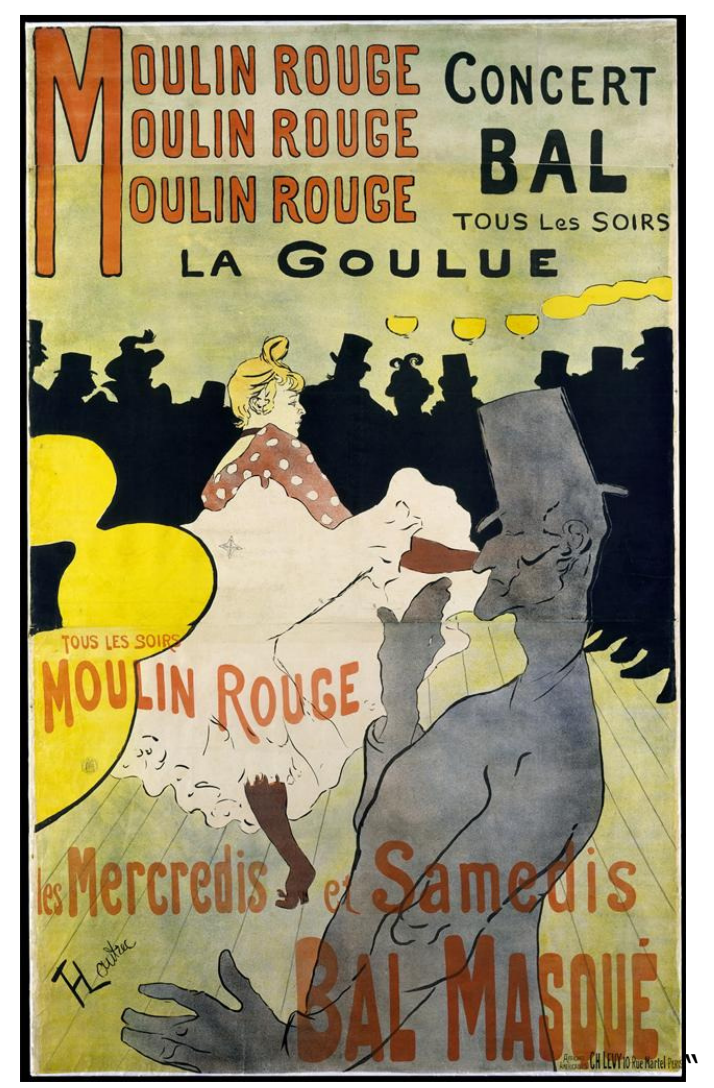

Figure 1.

Toulouse-Lautrec, H. de (1891) Moulin Rouge: La Goulue. Lithograph printed in four colors. Three sheets of wove paper, $189.99 \mathrm{~cm} \times 116.51 \mathrm{~cm}$.

The Metropolitan Museum of Art, Harris Brisbane Dick Fund, 1932 (32.88.12) Image (c) The Metropolitan Museum of Art

In Design History terms a study of a poster such as this might involve: a visual analysis of the image, comparison with other posters by Toulouse-Lautrec, and with other posters by contemporaries such as Chéret for consideration of style and treatment. The development of lithography as a print process and implications for this image would be highlighted as would details about the role of the poster and its commission. Finally, contextual information about Toulouse-Lautrec 's background and personality, life in Montmartre, and relationships with his subjects might be included. It would most likely concentrate on the designer/author as central but contextualise this in relation to technology, materials, and address some social aspects. This would undoubtedly be a useful account.

So what might Visual Culture offer to extend this understanding beyond the scope of graphic design history? It would probably contextualise in relation to developments of the late nineteenth century western industrialised culture; this could include: 
photography, the advent of electricity, image projection, the growth of the illustrated press, advertising, design, packaging, increased leisure time, commodity consumption and display. (Editorial, 2008). All of these aspects would be relevant to Paris at the time of this poster.

"....ideas and information came to be mediated through this fabricated, sensory environment of images, displays, and sights. In such an environment no one medium or mode of visual representation stood alone, fed only by its own traditions." (Editorial, 2008,p.115)

This is an important point and would suggest that the analysis must look sideways as it were, beyond posters and graphic design to capture visual experience. If we follow in the footsteps of the venerable Alpers and Baxandall for example, we should attend to the visual knowledge that viewers of the poster might have acquired through the lived social and economic realities of their lives, which would have made the image meaningful.

As many scholars of the late nineteenth century have shown, Paris was a modern metropolis, and in that sense a "place of visual encounter and experience" (Robins, 1996,p130) where significant developments in urban space and planning were key to formations of consumption and leisure. If the poster is located in this complex moment of modernity, where processes of social, economic and cultural change had resulted in a new visual landscape, and, new viewing practices what was this landscape like and what kinds of attention might an advertisement, or an entertainment poster have received?

Other questions to explore are related to how the new cabaret culture would have been viewed by its contemporaries. Who were its clientele? What social and entertainment practices and pleasures were permitted, and what might have been the motivations for going to the Moulin Rouge for women as well as men? These issues would allow us to investigate the audience for the poster. The use of star acts of their day (celebrity culture as it were) to lure customers in, already tells us something about who was hailed by the poster, the kind of cultural knowledge it drew on, and what these celebrities represented.

In considering the visual conventions the poster draws on and the cultural histories they relate to, one might break it down and take each aspect: the figure of the dancer of the can-can in the centre, the cut off figure of Valentin in the foreground, the striking use of silhouette across the middle of the design anonymising the audience, the stylised 
lights, the repeated type, the signature of Lautrec. Each of these can be explored - for example the cut off figure of Valentin may be referenced to the relatively new photographic conventions emerging; whilst traditions such as the silhouette and its popularity in nineteenth century visual culture through shadow theatre and its relation to cabaret, and other popular forms of live entertainment, are culturally specific (Forgione, 1999).

This is but a sketch of how one might start to think through a visual cultural approach to graphic design but it shows a number of things. Firstly the necessity to draw on other disciplines and bring together existing scholarship and ideas to open up greater understanding of the subject. This might include art history, cultural theory, cultural anthropology, and social geography for example. Much of the work will exist but it has to be connected, and making these connections, bringing these understandings to bear on graphic design, is a large part of what remains to be done. New research will flow from the unanswered questions but models exist from Visual Culture to assist. Visual Culture would complement classic graphic design history not threaten it. As this example shows, thinking about the complex relations between visual images and experiences enriches our understanding of graphic design. The selection of an iconic poster (a "milestone" according to Meggs p.234) was deliberate as one of the main objections to Visual Culture from art historians was the perceived threat to great works, which they felt would all be reduced to the same level. Here is an authored great work- is it reduced, diminished in any way by the approach I am suggesting? But Visual Culture will elucidate contemporary, unauthored graphic design as usefully as this famous nineteenth century exemplar: the framework is as relevant in the context of screen culture and the new, shifting spaces of graphic design. That is one of the many reasons why we should engage with it as appropriate to the field.

I have shown in this paper that visual cultural theorists inexplicably ignored graphic design, and that design historians and indeed graphic design historians, inexplicably ignored Visual Culture and its debates. I have argued for its relevance and hope to have made a case for its potential. Caught between disciplines- underplayed by the design academy and not addressed by the cultural/media studies academy graphic design hovers, underdeveloped but worthy of a stronger intellectual presence. 
Notes

1. There has been discussion over the confusion of the term Visual Culture denoting both an academic approach, and, its object of study (see Walker \& Chaplin 1997 p1), however over time Visual Culture has come to be recognised as an approach and I use it in this context.

2. See the recent article in Design Observer by Rick Poynor "Out of the Studio: Graphic Design History and Visual Studies" (2011) where he identifies a number of recent important works on Graphic Design History including Hollis' 2006 "Swiss Graphic Design: The origins and growth of an international style" and Heller 's 2008 "Iron Fists:

branding the $20^{\text {th }}$ century totalitarian state" ; and, the response on the website to that article from Steve Heller himself who identifies further examples of published work of note.

3. See Design Issues volume 11 no1, 1995. Also it would be remiss not to mention the Visible Language series on graphic design published in 1994-95, in three volumes, "New Perspectives: Critical Histories of Graphic Design", which though significant in its contribution did not address Visual Culture specifically.

4. See the 1990 publication Cranbrook Design: The New Discourse which though self-promoting had significant impact in dissemination of the ideas, and the article "A Brave new World: Understanding Deconstruction" by Byrne and Witte published in Print magazine in the same year. Lupton and Miller's "Deconstruction and Graphic Design: History Meets Theory" reflects back on the phenomenon a few years later in 1994.

\section{References}

Alpers, S. (1996). Response to Visual Culture Questionnaire. October, 77,26

Batchen, G. (2008) Snapshots: Art history and the ethnographic turn. Photographies, 1(2), 121-142

Baxandall, M (1974) Painting and Experience in fifteenth century Italy: a primer in the social history of pictorial style. London: Oxford University Press

Berger, J. ( 1972) Ways of Seeing. London: Harmondsworth, BBC; Penguin

Byrne, C. \& Witte. M (1990) A Brave new World: Understanding Deconstruction. Print 44 (6) 80-203 
Darley, A. (2000). Visual Digital Culture: Surface play and spectacle in new media genres. London: Routledge

Design Issues, (1995) 11(1)

Editorial. (2008) Photographies, 1(2), 115-120

Edwards, E. (2001) Raw histories : photographs, anthropology and

museums. Oxford: Berg

Evans, J. \& Hall, S. (Eds.). (1999). Visual Culture: The Reader.

London: Sage

Forgione, N. (1999) "The Shadow Only": Shadow and Silhouette in Late Nineteenth Century Paris . The Art Bulletin. 81 (3),490 - 512

Foster, H (Ed.). (1988). Vision and Visuality. Seattle: Bay Press.

Heller, S. (2008) Iron Fists: branding the $20^{\text {th }}$ century totalitarian state. London: Phaidon

Heller, S. (2011,January 11). Re: Out of the studio: Graphic Design History and Visual Studies. [online comment]. Retrieved from http://observatory. designobserver.com/entry.html?entry $=24048$ Hollis, R. (1994). Graphic design: a concise history. London: Thames \& Hudson

Hollis, R. (2006) Swiss Graphic Design: the origins and growth of an international style. London: Laurence King Jay, M. (2005). Introduction to Show and Tell. Journal of Visual Culture 4 (2): 139-143

Jenks, C. (Ed.). (1995). Visual Culture. London and New York: Routledge.

Julier, G. (2006). From Visual Culture to Design Culture. Design Issues 22 (1) 64-76

Lister, M., Dovey, J., Giddings, S., Grant, I., Kelly, K. (2009). New Media: a Critical Introduction. ( $2^{\text {nd }}$ Ed.) London: Routledge. Lupton, E. and Miller, J.A. (1994). Deconstruction and Graphic Design: History Meets Theory. Visible Language 28(4) 346-366 Manovich, L. (2001). The Language of New Media. Cambridge, Mass.: MIT Press Meggs, P. (1983) A History of Graphic Design. London: Allen Lane McCoy, K. and Mc Coy. M. (Eds.). (1990) Cranbrook Design: The New Discourse. New York: Rizzoli

Mirzoeff, N. (1999) An Introduction to Visual Culture. London:

Routledge

Morra, J., \& Smith. M. (Eds.) (2006). Visual Culture. Critical Concepts in Media and Cultural Studies. London and New York: Routledge New Perspectives: Critical Histories of Graphic Design, Special Project of Visible Language in Three Issues, Visible Language 28 (3),28 (4), 29(1) 
Poynor, R. (2011, January 10). Out of the Studio: Graphic Design History and Visual Studies. Retrieved from

http://observatory.designobserver.com/entry.html?entry $=24048$

Questionnaire on Visual Culture. (1996) October 77, 3-4,25-70

Robins, K. (1996). Into the Image. London : Routledge.

Walker, J.A. \& Chaplin, S. (1997). Visual Culture: An Introduction.

Manchester: Manchester University Press. 